\title{
Ecotourism impacts on the behaviour of whale sharks: an experimental approach
}

\author{
Austin N. Montero-Quintana, J. Abraham Vázquez-Haikin \\ Thomas Merkling, Pierrick Blanchard and Marcela Osorio-Beristain
}

\begin{abstract}
Tourists approaching wild animals can potentially cause disturbance as a result of the perceived predation risk. Risk effects arise when prey alter their behaviour in response to predators. This response may carry costs through its impact on fitness-related activities such as foraging. We recorded behavioural responses of whale sharks Rhincodon typus to experimental vessel and swimmer approaches. We simulated the disturbance caused by ecotourism in the foraging site of this planktivorous fish in Bahia de Los Angeles, Gulf of Baja California, Mexico. Stress-related behaviours (vigilance, change of direction, diving and acceleration) were more common directly after both types of disturbance than before, in particular after approach by a swimmer. Individuals were more likely to be vigilant when they were new to the bay, but we did not find evidence of within-season behavioural habituation. Sharks were $24 \%$ more likely to forage before human stimuli than after. Our study highlights negative effects of vessel and swimmer approaches on whale shark behaviour, with a short-term increase in stress-related behaviours potentially carrying energetic costs, combined with a decrease in food intake following the disturbance. Our results indicate concerns about the impact of ecotourism on large fish species. An important next step would be to determine whether these short-term behavioural responses to the perception of predation risk negatively affect fitness. Among other guidelines, we recommend preventing swimmers from approaching if whale sharks stop feeding when a vessel approaches.
\end{abstract}

Keywords Bahia de Los Angeles, disturbance, ecotourism, Mexico, Rhincodon typus, risk effects, stress-related behaviours, vigilance

Austin N. Montero-Quintana and Marcela Osorio-Beristain (Corresponding author) Centro de Investigación en Biodiversidad y Conservación, Universidad Autónoma del Estado de Morelos, Avenida Universidad 1001, Chamilpa, Cuernavaca, Morelos, CP 62209, Mexico

E-mail mosorio@uaem.mx

J. Abraham VÁzquez-Haikin Grupo de monitoreo comunitario Pejesapo, Bahía de los Ángeles, Baja California, Mexico

Thomas Merkling* and Pierrick Blanchard Laboratoire Evolution et Diversité Biologique, Université Paul Sabatier, Toulouse, France

${ }^{*}$ Present address: Department of Natural Resource Sciences, McGill University, Ste Anne-de-Bellevue, Quebec, Canada

Received 30 June 2017. Revision requested 21 September 2017.

Accepted 4 January 2018. First published online 13 August 2018

\section{Introduction}

Derception of predation risk induces physiological stress - (Brown \& Kotler, 2004; Clinchy et al., 2004), stressrelated behavioural responses such as avoidance/escape and vigilance (Childress \& Lung, 2003; Armitage, 2017), and changes in patterns of aggregation (Winnie \& Creel, 2007) or movement (Sih \& McCarthy, 2002). These responses are expected to conflict with other important fitness-related activities such as foraging, reinforcing energetic constraints on reproduction or survival (Sinclair \& Arcese, 1995; Brown \& Kotler, 2004). Because animals often perceive human presence as a form of predation risk, they react by displaying typical antipredator behavioural responses (Frid \& Dill, 2002). For example, tourismrelated activities are known to influence vigilance patterns (Beauchamp, 2015). In marine animals that spend part of their biological cycle inshore as they feed, or reproduce near the shoreline, the potential for these disturbances increases with increased tourism. Following disturbance caused by marine tourism, animals shift from fundamental behavioural activities to vigilance or escape behaviour. For example, in bottlenose dolphins Tursiops spp. off the coast of Scotland, boat presence reduced foraging activity by $49 \%$ (Pirotta et al., 2015). In Shark Bay, Australia, experimental boat approaches to dolphin Lagenorhynchus obscurus pods elicited more erratic travel direction compared to travel behaviour before and after approaches (Bejder et al., 2006). Humpback whales Megaptera novaeangliae off the coast of Ecuador increased their swimming speed in the presence of boats (Scheidat et al., 2004). Harp seal Phoca groenlandica pups spent less time resting, and the vigilance time of their mothers increased, in response to tourist presence, at the expense of suckling time for the pups (Kovacs \& Innes, 1990). A meta-analysis comparing cetacean responses to vessel approach across 15 studies (Senigaglia et al., 2016) found consistent evidence of disruptions of activity budgets and path directionalities. The viability of some cetacean populations has been affected, with behavioural disruptions leading to a decrease in female reproductive success and a consequent decrease in population size (Lusseau et al., 2006; Currey et al., 2009).

Here, we focus on the whale shark Rhincodon typus, categorized as Endangered on the IUCN Red List (Pierce \& Norman, 2016), in Bahia de Los Angeles, Gulf of Baja California, in northern Mexico. We experimentally mimicked the effect of ecotourism, allowing us to standardize 
the sources of disturbances (i.e. the approaches of vessels and swimmers) and investigate four aspects of whale shark-tourist interactions: (1) vigilance behaviour, (2) behaviours that reflect stress, (3) foraging probability, and (4) habituation to disturbance.

We investigated vigilance behaviour for two reasons. Firstly, monitoring vigilance is a more specific proxy of risk perception than, for example, a change in direction of a foraging individual, which may only reflect a change of foraging route following food distribution; the observation of the same individuals both with and without human stimulus allowed us to assess to what extent human approach caused changes in vigilance investment. Secondly, vigilance may be a reliable proxy of potential foraging costs (Blanchard \& Fritz, 2007). We hypothesized that the probability of displaying behaviours expected to reflect stress (vigilance, changes in direction, diving or acceleration) should increase after an experimentally simulated tourist approach. To investigate whether tourist trips affect sharks foraging probability, we hypothesized that if tourist trips affect the perception of risk, the probability that whale sharks would be foraging should decrease following tourist approaches. As whale sharks are individually recognizable, we investigated whether they could habituate to disturbance: for individuals observed several times over the course of one season, we evaluated whether disturbance-related behaviours decreased in subsequent approaches compared to the first approach.

\section{Study area}

The study was carried out in Bahia de los Angeles, Gulf of Baja California, México $\left(28^{\circ} 59^{\prime}-29^{\circ} 03^{\prime} \mathrm{N}, 113^{\circ} 30^{\prime}-113^{\circ} 26^{\prime} \mathrm{W}\right)$, a regular location for whale shark aggregation during JuneNovember. This bay drains into the Gulf of California and is an important foraging habitat, with patches of high copepod densities (Nelson \& Eckert, 2007; Hernández-Nava \& Alvarez-Borrego, 2013). At the study site whale sharks can be observed approaching 2-10 $\mathrm{m}$ from the shore (authors, pers. obs.). Our study was conducted in SeptemberNovember 2014, when whale shark sightings peak. This large planktivorous fish requires high density prey patches to make feeding energetically viable (Ronher et al., 2015). In the tropics, they face the challenge of finding sufficient food in an oligotrophic environment in which prey are sparsely distributed and their quantity and location are dynamic in space and time (Ronher et al., 2015). The occurrence of seasonal aggregations of whale sharks in the bay, following prey patches, has stimulated the development of ecotourism focused on these animals, with a potential cost for the sharks when disturbed during foraging. The Official Mexican Standard (Norma Official Mexicana: NMX-AA-142-SCFI-2008) provides guidelines for ecotourism activities, focusing on whale sharks while they are in Mexican waters. Touching or interrupting the activity of whale sharks is prohibited. However, in Bahia de los Angeles the presence of park rangers allowed to penalize these behaviours is restricted to a few days per month, and only outside the whale shark sighting season.

\section{Methods}

\section{Experimental design}

Whale sharks were located during the day in the area that tourism operators commonly use for trips. We used a $7 \mathrm{~m}$ panga (a skiff-like vessel with an outboard motor), driven by experienced tour operators, to approach whale sharks that were spotted at the water surface, typically while foraging. Vessels approached from behind and to one side of the whale shark, travelling at no more than 8 miles/h (c. $13 \mathrm{~km} / \mathrm{h}$ ), as established in the tourist operators regulations (Rodríguez-Dowdell et al., 2007). We only recorded encounters when whale sharks were at the surface and were first spotted from 10-20 $\mathrm{m}$. We discarded encounters in which sharks appeared close to the vessel. A total of three different swimmers performed the trials, but only one swimmer participated per trial. The swimmer used snorkeling equipment for every interaction and was experienced in monitoring whale sharks. In each trial the swimmer always dived after the vessel approached, and swam from behind or approached on one side of the animal and at a low speed (slower than the vessel speed).

Whale sharks can be individually identified from the unique patterns of white dots and stripes on their dorsal surface. Photographs of whale sharks have been compiled since 2007 by the tourist management group PEJESAPO. We used this database to identify the individuals monitored. We used scan-sampling observations (Altmann, 1974) to record the behaviours of whale sharks in response to experimental approaches.

Whale shark behaviour was recorded by one observer, from the vessel, during four periods: immediately when the whale shark was sighted (i.e. at $10-20 \mathrm{~m}$ from the vessel) and before the vessel approached, after the vessel approached (until 4-5 $\mathrm{m}$ from the shark), after the swimmer approached (until $0.5-5 \mathrm{~m}$ from the shark), and (4) after human stimuli (i.e. after the swimmer returned to the vessel and the vessel was $>10 \mathrm{~m}$ from the whale shark). The observer recorded the following behaviours: foraging, vigilance, change of direction, diving and acceleration. Foraging individuals referred to animals gulping large amounts of water while swimming slowly or floating just below the water surface, following Ketchum et al. (2013) and Nelson \& Eckert (2007). Vigilance was recorded when a whale shark was floating immobile at a shallow depth, with its mouth closed, sometimes orienting its head towards the 
vessel or swimmer (a behaviour referred to as alert by Cubero-Pardo et al., 2011). Diving was recorded when individuals moved deeper in the water column. Acceleration was recorded when animals increased their horizontal swimming speed. We recorded date and time of sighting, location (using a global positioning system), sex (obtained by the swimmer diving under the whale shark, looking for presence or absence of claspers), and size of whale sharks observed. Size was determined by comparing the whale shark's total body length with the length of the vessel and swimmer (Nelson \& Eckert, 2007; Ketchum et al., 2013). In September 2014 hurricane Odile hit the study area, significantly reducing tourism during the next 2 months, enabling us to perform the experimental trials without the confounding effect of approaches by tourists.

\section{Statistical analyses}

As the behaviour of each shark was recorded during four periods (see above) and as more than one individual could be observed on the same day, we included individual identity nested in observation date as random terms in all analyses, to avoid pseudoreplication. Mixed models were run using the lmes package (Bates et al., 2015) in $R$ 3.2.3. (R Development Core Team, 2013). All the response variables were binary. We used general linear mixed models (GLMMs) with a binomial distribution and logit link function, and with the same explanatory variables: the period of observation (before human stimuli, after vessel approach, after swimmer approach, after overall human stimuli), sex, whale shark length, and whether the individual had or had not previously been observed in the area. Because we were interested in the effect of tourists on whale shark behaviour and because of the limited sample size, we only considered two-way interactions involving the period of observation. As we did not find any habituation effect we included all the observations recorded on the same individuals in the first three analyses (see below). In the first two analyses we focused on the individuals for which we had data for the four periods, whereas for the third analysis we considered the first and last period only, therefore increasing sample size. This is explained below. We discarded data for eight individuals of unknown sex. A total of 77 individuals were observed at least once.

Model selection began with a full model and terms were successively removed, beginning with interaction effects. We tested the change in deviance after removal of a term using a $\chi^{2}$ test. Whenever an interaction was tested, the main effects comprising the interaction were retained in the model. As probability values obtained from likelihood-ratio tests on GLMMs are not robust (Bolker et al., 2009), we retested all significant effects using a bootstrap method (with 200 replications): these probability values are indicated as $\mathrm{P}_{\text {boot }}$.
Model predictions and standard errors were obtained using the AICcmodavg package in $R$.

Are whale sharks more vigilant when approached? The binary response variable was the state of vigilance of the individual: vigilant/not vigilant. However, because sharks were never vigilant before human stimuli and only one was vigilant after the vessel departed, models did not necessarily converge. Hence we first performed a $\chi^{2}$ test to investigate the relationship between being vigilant or not and the four observation periods, focusing only on the 44 individuals with data for all four periods (176 observations). We ran the GLMM on the two periods with sufficient variability in whale shark vigilance behaviour (after vessel and after swimmer; 130 observations).

Are whale sharks more stressed when approached? The binary response variable was the display of behaviours expected to indicate stress (vigilance, change of direction, dive or acceleration): stress display/no stress display. Because of the absence of variability in shark stress before and after human stimuli (almost no sharks were stressed during these periods), we used the approach described above, and sample sizes are the same.

Do people affect whale shark foraging? The binary response variable was the foraging behaviour of the individual: foraging/not foraging. We compared the observation period before and after overall human stimuli (i.e. two observations per individual per session; $\mathrm{N}=68$ individuals, 200 observations).

Do whale sharks exhibit within-season behavioural habituation? We re-ran the above three analyses focusing on individuals observed at least twice in the season (twice: $\mathrm{N}=\mathbf{2 2}$ individuals; three times: $\mathrm{N}=10$ individuals). We discarded individuals observed four and five times, as this applied to only two individuals. Given the small sample size, we only considered two-way interactions involving observation order. Because of convergence issues, we standardized all explanatory variables (except observation order, as it had three levels) using the arm package in $R$ (Gelman, 2008).

\section{Results}

Are whale sharks more vigilant when approached? No individuals (of 44) were vigilant before human stimuli and only one after, whereas vigilance was more common during approach by the vessel and by a swimmer $\left(\chi_{3}^{2}=40.97\right.$, $\mathrm{P}<$ o.00o1; Fig. 1a). Whale sharks were $56 \%$ more likely 

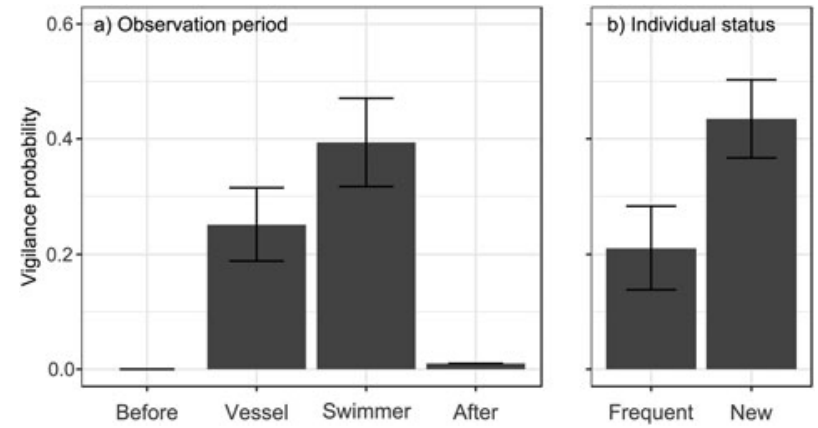

FIG. 1 Probability of being vigilant (GLMM prediction \pm SE) in relation to (a) observation period (after vessel or swimmer approach, together with data before and after human stimuli, for comparison), and (b) an individual's status in the population (previously observed or newly observed at the location).

to be vigilant after a swimmer's approach than after that of a vessel (estimate $\beta 0.70 \pm$ SE $0.38, \mathrm{P}_{\text {boot }}=0.044$ ). They were also $106 \%$ more likely to be vigilant when they were new individuals at the location than when they had been seen previously $\left(\beta\right.$ 1.09 \pm SE 0.45, $P_{\text {boot }}=0.010$; Fig. 1b). Neither sex nor length had a significant effect (all $\mathrm{P}>0.11$ ) and none of the interactions with observation period (after vessel or after swimmer) significantly affected shark vigilance (all $\mathrm{P}>0.84$ ).

Are whale sharks more stressed when approached? As with vigilance behaviour, no individuals (of 44) were stressed before human stimuli and only four after, whereas stress was more common after encounters with a vessel or a swimmer $\left(\chi_{3}^{2}=68.72, \mathrm{P}<0.0001\right.$; Fig. 2). Observation period was the only significant predictor (all other $P>0.15)$ : sharks were $67 \%$ more likely to show stress after approach by a swimmer than after approach by a vessel ( $\beta$ $1.37 \pm \mathrm{SE}$ 0.46, $\mathrm{P}_{\text {boot }}=$ 0.010; Fig. 2). None of the interactions with observation period significantly affected shark stress (all P > 0.14).

Do people affect whale shark foraging behaviour? Whale sharks were $24 \%$ more likely to forage before human stimuli than after (before: $\beta$ o.78 \pm SE 0.08 ; after: $\beta$ o.63 $\pm 0.08 ; P_{\text {boot }}=0.005$ and there was a non-significant tendency for longer individuals to be observed foraging ( $\beta$ $0.64 \pm$ SE 0.25; $P_{\text {boot }}=0.08$ ). None of the interactions with observation period significantly affected the probability of observing whale sharks foraging (all $\mathrm{P}>0.10$ ).

Do whale sharks exhibit within-season behavioural habituation? There was no evidence of behavioural habituation, regardless of the behaviour considered: none of the interactions between observation order and other variables were significant (all $\mathrm{P}>0.37$ ).

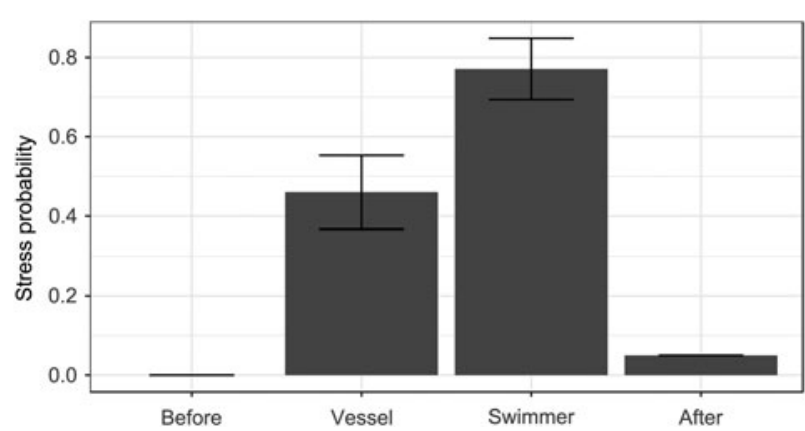

Fig. 2 Probability of exhibiting stress-related behaviour (see text for details; GLMM prediction \pm SE) in relation to the observation period (after vessel or swimmer approach, together with data before and after human stimuli, for comparison).

\section{Discussion}

Risk effects arise when prey alter their behaviour in response to predators, and this response carries costs (Creel \& Christianson, 2008). In Bahia de los Angeles, mimicking ecotourism, in the form of vessels and swimmers approaching whale sharks, induced stress-related behavioural responses in both males and females. Both vessels and swimmers increased the probability of displaying vigilance, and stress-related behaviours more generally. Swimmers appeared to be more stressful to whale sharks than vessels. However, this could be a cumulative effect, as in our experimental design the swimmer stimulus always followed the vessel stimulus. It would be of value to separate each stimulus, to understand better the effects of each type of approach, but it is unlikely that in actual tourism these two stimuli would be presented in isolation or in a different order and therefore the sequence of presentation used here is the most relevant for an understanding of whale shark-tourist interactions in practice. Although vigilance may allow an animal to collect more information about a potential threat, changing direction, diving or accelerating suggests a motivation to move away from human stimulus. Moving away from boats was registered in dolphins Tursiops truncatus (Lusseau, 2004): if dolphin-boat interactions were longer than a mean of 68 minutes, they modified their activity to escape from the area. A meta-analysis showed that variation in path sinuosity captured cetacean response to vessel presence, suggesting that this response may reflect an attempt to avoid vessels without leaving the area (Senigaglia et al., 2016).

We found that after a simulated tourist trip the probability that a whale shark would forage was decreased, with the potential for long-term negative effects on individuals as a result of reduced food intake. However, given that sharks were first spotted when at the surface, typically during foraging, we cannot exclude the possibility that some sharks naturally stopped foraging irrespective of human presence. For the dusky dolphin Lagenorhynchus obscurus, boat presence negatively affected long-term foraging efficiency, as 
they stopped feeding, to travel (Dans et al., 2008). If copepod abundance is subject to dynamic and seasonal changes in Bahia de los Angeles (Lavaniegos, et al., 2012), a likely cost of disturbance to whale sharks, particularly during foraging bouts, is lowered energy intake. This potentially translates into a reduction in reproductive output or in long-term survival (Lima, 1998), with local consequences on population trends.

The analysis of intra-seasonal habituation suggested no such effect in whale sharks. However, 2-3 observations may be insufficient to detect such a pattern. Moreover, what we considered the first encounter could have been the first for some individuals but not for others, as whale sharks could have had encounters in other parts of the Gulf. Our results on the effect of previous sightings in the area on vigilance do not necessarily mean there is habituation (although this may be the case after $<_{3}$ experiences with tourists; i.e. at the end of the season), but rather could suggest that more sensitive individuals do not return to this area of high tourist pressure. Further studies are needed to discriminate between these possibilities. In Ningaloo Reef, Australia, there was no evidence that high exposure to tourism led to inter-annual decreases of whale sharks in the bay, which was interpreted as individuals having become accustomed to encounters with tourists (Sanzogni et al., 2015). Individuals exhibiting site fidelity could be vulnerable to human disturbance, and selection may favour those individuals with personality traits allowing them to habituate to encounters with tourists.

We found a non-significant trend for larger individuals to feed more, regardless of the period of observation (before or after the approach procedure). A meta-analysis showed that small cetacean species were less likely to rest in the presence of vessels than larger species (Senigaglia et al., 2016). In other vertebrates, the best predictor of the direction and magnitude of tolerance to human approaches is body size: for example, larger birds are more tolerant than smaller ones (Samia et al., 2016).

In conclusion, it remains to be determined whether short-term behavioural responses to perception of predation risk negatively affect fitness. Declines in whale shark sightings have been reported in several locations. In western Australia abundance declined by 40\% from 1995 to 2004 (Mau \& Wilson, 2005; Bradshaw et al., 2008), and anecdotal reports from Belize suggest that as tourism has increased, whale sharks sightings have decreased (Graham, 2007). The effects of exploitation via non-lethal effects of ecotourism on the largest fish need to be measured both in terms of the economic benefits for local people and effects on the behaviour, physiology and, ultimately, fitness of the animals. Our results suggest that preventing swimmers from approaching, if whale sharks stop feeding when a vessel approaches, could avoid further increasing stress. This suggestion is also in the Mexican guidelines regulating ecotourism activities focusing on whale sharks (Norma Official Mexicana: NMX-AA-142-SCFI-2008). As whale sharks can also be observed close to the shore, tourist operators could instead develop walking tours to observe whale sharks with fixed telescopes, thereby reducing disturbance. Future studies could also investigate the way distance to vessel and swimmer shapes risk perception by whale sharks, which would facilitate guidelines for operators regarding minimum distances.

Acknowledgements This work was funded by the Mexican Commission on Natural Protected Areas. We thank the Pejesapo monitoring group and PRONATURA Noroeste for logistical support. MOB is grateful to ECOLAB of University Paul Sabatier for its support during her sabbatical stay. The laboratory EDB is part of the Laboratoire d'Excellence TULIP (ANR -10-LABX-41). Lynna Kiere reviewed the English. José Arce-Smith, Ricardo Arce-Navarro and Joel Prieto-Villavicencio drove the vessel during trials. Ian Velazco-Espinoza and Ricardo Arce-Navarro participated in fieldwork. We are grateful to the Facultad de Ciencias Biológicas, Universidad Autónoma del Estado de Morelos, and to Elisabet Wehncke and Adalberto Aguilar for their critiques.

Author contributions Conception and design of the experiment: $\mathrm{MOB}, \mathrm{AMQ}$; recording of the data: AMQ, AVH; data analysis: $\mathrm{PB}$, TM; discussion of results: all authors; writing: $\mathrm{MOB}$; revisions: $\mathrm{PB}$ and TM.

\section{Conflicts of interest None.}

Ethical standards We complied with the Oryx Code of Conduct for authors.

\section{References}

Altmann, J. (1974) Observational study of behavior: sampling methods. Behavior, 49, 227-267.

Armitage, K.B. (2017) Badger predation on yellow-bellied marmots. The American Midland Naturalist, 151, 378-387.

Bates, D., Mächler, M., Bolker, B.M. \& Walker, S.C. (2015) Fitting linear mixed-effects models using lme4. Journal of Statistical Software, 67,48 .

Beauchamp, G. (2015) Animal Vigilance: Monitoring Predators and Competitors. Elsevier, Amsterdam, The Netherlands.

Bejder, L., Samuels, A., Whitehead, H. \& Gales, N. (2006) Interpreting short-term behavioural responses to disturbance within a longitudinal perspective. Animal Behaviour, 72, 1149-1158.

Blanchard, P. \& Fritz, H. (2007) Induced or routine vigilance while foraging. Oikos, 116, 1603-1608.

Bolker, B.M., Brooks, M.E., Clark, C.J., Geange, S.W., Poulsen, J.R., Stevens, M.H.H. \& Whie, J.S.S. (2009) Generalized linear mixed models: a practical guide for ecology and evolution. Trends in Ecology and Evolution, 24, 127-135.

Bradshaw, C., Fitzpatrick, B.M., Steinberg, C.C., Brook, B.W. \& Meekan, M.G. (2008). Decline in whale shark size and abundance at Ningaloo Reef over the past decade: the world's largest fish is getting smaller. Biological Conservation, 14, 1894-1905.

Brown, J.S. \& Kotler, B.P. (2004) Hazardous duty pay and the foraging cost of predation. Ecology Letters, 7, 999-1014. 
Childress, M.J. \& Lung, M. (2003) Predation risk, gender and the group size effect: does elk vigilance depend upon the behaviour of conspecifics? Animal Behaviour, 66, 389-398.

Clinchy, M., Zanette, L., Boonstra, R., Winfield, J.C. \& Smith, J.N.M. (2004) Balancing food and predator pressure induces chronic stress in songbirds. Proceedings of the Royal Society B, 271, $2473-2479$.

Creel, S. \& Christianson, D. (2008) Relationships between direct predation and risk effects. Trends in Ecology and Evolution, 23, 194201.

Cubero-Pardo, P., Herron, P. \& González-Perez, S. (2011) Shark reactions to scuba divers in two marine protected areas of the eastern tropical Pacific. Aquatic Conservation: Marine and Fresh Water Ecosistems, 21, 239-246.

Currey, R.J.C., Dawson, S.M. \& Slooten, E. (2009) An approach for regional threat assessment under IUCN Red List criteria that is robust to uncertainty: the Fiordland bottlenose dolphins are Critically Endangered. Biological Conservation, 142, 1570-1579.

Dans, S.L., Crespo, E.A., Pedraza, S.N., Degrati, M. \& Garaffo, G.V. (2008) Dusky dolphin and tourist interaction: effect on diurnal feeding behavior. Marine Ecology Progress Series, 369, 287296.

Frid, A. \& Dill, L. (2002) Human-caused disturbance stimuli as a form of predation risk. Ecology and Society, 6, 11-26.

Gelman, A. (2008) Scaling regression inputs by dividing by two standard deviations. Statistics in Medicine, 27, 2865-2873.

Graham, R.T. (2007) Whale sharks of the western Caribbean: an overview of current research and conservation efforts and future needs for effective management of the species. Gulf and Caribbean Research, 19, 149-159.

Hernández-Nava, M.F. \& Alvarez-Borrego, S. (2013) Zooplankton in a whale shark (Rhincodon typus) feeding area of Bahía de los Ángeles (Gulf of California). Hidrobiológica, 23, 198208

Ketchum, J.T., Galván-Magaña, F. \& Klimley, A.P. (2013) Segregation and foraging ecology of whale sharks, Rhincodon typus, in the southwestern Gulf of California. Environmental Biology of Fishes, 96, 779-795.

Kovacs, K.N. \& Innes, S. (1990) The impact of tourism on harp seals (Phoca groenlandica) in the Gulf of St. Lawrence, Canada. Applied Animal Behaviour Science, 26, 15-26.

Lavaniegos, B.E., Heckel, G. \& Ladron de Guevara Porras, G. (2012). Seasonal variability of copepods and cladocerans in Bahía de los Ángeles (Gulf of California) and importance of Acartia clausi as food for whale sharks. Ciencias Marinas, 38, 11-30.

LimA, S.L. (1998) Nonlethal effects in the ecology of predator-prey interactions. BioScience, 48, 25-34.

Lusseau, D. (2004) The hidden cost of tourism: detecting long-term effects of tourism using behavioral information. Ecology and Society, 9, 2

Lusseau, D., Slooten, L. \& Currey, R.J.C. (2006) Unsustainable dolphin-watching tourism in Fiordland, New Zealand. Tourism in Marine Environments, 3, 173-178.
MAU, R. \& WiLSON, E. (2005) Industry trends and whale shark ecology based on tourism operator logbooks at Ningaloo Marine Park. In The First International Whale Shark Conference: Promoting International Collaboration in Whale Shark Conservation, Science and Management (eds T.R. Irvine \& J.K. Keesing), p. 116. CSIRO, Canberra, Australia.

Nelson, J.D. \& Eckert, S.A. (2007) Foraging ecology of whale sharks (Rhincodon typus) within Bahía de Los Angeles, Baja California Norte, México. Fisheries Research, 84, 47-64.

Pierce, S.J. \& Norman, B. (2016). Rhincodon typus. The IUCN Red List of Threatened Species 2016. e.T19488A2365291. Http://dx.doi. org/10.2305/IUCN.UK.2016-1.RLTS.T19488A2365291.en [accessed 28 June 2018].

Pirotta, E., Merchant, N.D., Thompson, P.M., Barton, T.R. \& Lusseau, D. (2015) Quantifying the effect of boat disturbance on bottlenose dolphin foraging activity. Biological Conservation, 181, 82-89.

R Development Core Team (2013) R: A Language and Environment for Statistical Computing. R Foundation for Statistical Computing, Vienna, Austria.

Rodríguez-Dowdell, N., Enríquez-Andrade, R. \& CÁrdenas-Torres, N. (2007) Property rights-based management: whale shark ecotourism in Bahia de Los Angeles, Mexico. Fisheries Research, 84, 119-127.

Ronher, C.A., Armstrong, A.J., Pierce, S.J., Prebble, C.E.M., Cagua, E.F., Cochran, J.E.M. et al. (2015) Whale sharks target dense prey patches of sergestid shrimp off Tanzania. Journal of Plankton Research, 37, 352-362.

Samia, D.S.M., Blumstein, D.T., Stankowich, T. \& Cooper, W.E. (2016) Fifty years of chasing lizards: new insights advance optimal escape theory. Biological Reviews, 91, 349-366.

Sanzogni, R.L., Meekan, M.G. \& Meeuwig, J.J. (2015) Multi-year impacts of ecotourism on whale shark (Rhincodon typus) visitation at Ningaloo Reef, Western Australia. PLoS ONE, 10(9), eo127345.

Scheidat, M., Castro, C., González, J. \& Williams, R. (2004) Behavioural responses of humpback whales (Megaptera novaeangliae) to whale watching boats near Isla de la Plata, Machalilla National Park, Ecuador. Journal of Cetacean Research and Management, 6, 63-68.

Senigaglia, V., Christiansen, F., Bejder, L., Gendron, D., Lundquist, D., Noren, D.P. et al. (2016). Meta-analyses of whale-watching impact studies: comparisons of cetacean responses to disturbance. Marine Ecology Progress Series, 542, 251-263.

Sin, A. \& Mccarthy, T.M. (2002) Prey responses to pulses of risk and safety: testing the risk allocation hypothesis. Animal Behaviour, 63 , 437-443.

Sinclair, A.R.E. \& Arcese, P. (1995) Population consequences of predation-sensitive foraging: the Serengeti wildebeest. Ecology, 76, 882-891.

Winnie, J.A. \& CREel, S. (2007) Sex-specific behavioural responses of elk to spatial and temporal variation in the threat of wolf predation. Animal Behaviour, 73, 215-225. 